compared with a structured objective scoring system. We have adopted the latter because of the benefits of greater concordance between examiners on what the student is expected to achieve; a scoring framework can be used for training as well as a simple method for student feedback. The viva examination will be based, in part, upon the content of the logbook. A regular formalised system of student feedback through feedback forms and student staff meetings is in development and will act as a focus for subsequent course development.

The process of curriculum review is an arduous one, the major risk being that it will do little to improve the final product because the good students will always do well and the bad ones, badly. It does make the teachers reevaluate their methods and work more closely with their colleagues. The current mood of change is supported by the explosion of new teaching technology which may be a potent catalyst to ongoing changes in learning techniques for clinical medicine, although it is hard to see how the clinical process can be learned without the traditional 'apprenticeship' methods we all used.

\section{General Medical Council. Undergraduate medical education. The need for change. London: GMC, 1991. \\ 2 Lowry S. What's wrong with medical education in Britain? $B M \mathcal{F}$ 1992; 305: 1277-80. \\ 3 Lowry S. Curriculum design. BMF 1992; 305: 1409-11. \\ 4 General Medical Council. Tomorrow's doctors. Recom- mendations on undergraduate medical education. London: GMC, 1993. \\ 5 Lask B. Talking with children. Br $\mathcal{F}$ Hosp Med 1992; 47: 688-90. \\ 6 Lloyd BW, Barnett P. Use of problem lists in letters between hospital doctors and general practitioners. BMF 1993; 306: 247. \\ 7 McManus IC, Vincent CA, Thom S, Kidd J. Teaching com- munication skills to clinical students. BMF 1993; 306: 1322-7. \\ 8 Hull D, Johnston D, eds. Essential paediatrics. 2nd Ed.} Edinburgh: Churchill Livingstone, 1993.

\title{
Core knowledge, skills, and attitudes in child health for undergraduates
}

Department of Child Health, University of Glasgow, Royal Hospital for Sick Children, Yorkhill, Glasgow G3 8SJ J Y Paton F Cockburn

J Y Paton, F Cockburn

\begin{abstract}
Background
'We recommend the introduction of a core curriculum which defines the requirements that must be satisfied before a newly qualified doctor can assume the responsibilities of a pre-registration house officer'
\end{abstract}

... 'the memorising and reproduction of factual data should not be allowed to interfere with the primary need for fostering the critical study of principles and the development of independent thought' Tomorrow's Doctors ${ }^{1}$

Anxieties about the nature and content of undergraduate medical education in the UK have arisen regularly during most of the past century. The curriculum has long been recognised to be overloaded: too many facts, too little thinking. Recently, these anxieties have become more sharply focused and a complete review of the medical curriculum is under way. The General Medical Council (GMC) has decreed it should change, and in their outline recommendations entitled Tomorrow's Doctors, ${ }^{1}$ has described the underlying forces and set out a plan for change. A central step en route to the new leaner curriculum is the definition of a core containing only essential knowledge, skills, and attitudes.

\section{Why teach child health to undergraduates?}

'It is an essential rule that no teaching course or module should be planned without consideration of its role in the curriculum as a whole'. ${ }^{1}$

If a central aim of the core curriculum is to meet the requirements of a preregistration house officer, then there is, on one view, at least an argument against teaching child health to undergraduates. Thus if child health is to justify its place in the medical curriculum, its role and potential contribution to undergraduate education must first be clearly delineated.

\section{Why does child health merit inclusion in the core curriculum?}

There are several reasons why child health can justify its claim on undergraduates' time, and why it can contribute uniquely to 'the critical study of principles and the development of independent thought'. ${ }^{1}$

Firstly, the study of growth and development in medicine is analogous to the study of velocity and acceleration in physics. In paediatrics, illness occurs in the context of growth and development. In few other areas of medicine is 'time's arrow' as naturally present or pervasive. It is only with a knowledge of growth and development that the impact of environmental and genetic factors can be understood and a true appreciation of the origins of human health and disease achieved.

Secondly, public health is to figure prominently in the new core curriculum. Children have different diseases from adults. This different disease spectrum can help the undergraduate student to focus on important public health questions. In particular, what diseases affect children?, which are common?, what are the sources of information about health and illness?, how is 'health' measured?, is social 
disadvantage important?, how does the spectrum of illness change with time? It should be remembered that the most effective of all public health interventions is childhood immunisation. The organisation and evaluation of immunisation remain key tasks of child health. Other examples illustrating the emphasis on health are easy to find - childhood screening for metabolic diseases, and developmental screening. Indeed, the emphasis on the maintenance of health runs like a golden thread through paediatrics.

Thirdly, the study of child health also provides an opportunity to explore wider issues of public health. As society's 'canaries', children are exposed to the full blast of society's ills. It is not for nothing that infant mortality and morbidity rates are the best comparators of a nation's health. Recent research has focused on the study of the effects of physical and social environments on children's health, and how these effects are mediated.

Finally, there are also important themes identified as common to all curricula such as communications skills, handicap, disability, and rehabilitation, ${ }^{1}$ which are of central concern to all children's doctors.

\section{Defining a core curriculum in child health (see appendix)}

The core curriculum aims to represent a distillate of essential knowledge and skills and to promote the acquisition of attitudes necessary for the high standards of medical practice. What is its quintessence?

\section{(A) KNOWLEDGE OBJECTIVES - KNOWLEDGE} AND UNDERSTANDING

In child health, growth and development are central. Core knowledge, therefore, should encompass the effects of prenatal influences and the changes that occur at the time of birth together with the later physical, intellectual, emotional, and social growth and development of the child. It should also include the effects of disordered nutrition, diseases, and family dynamics on these processes.

To many undergraduates, paediatrics seems like a parade of exotic and bizarre disorders with little or no emphasis on commonplace diseases and their treatment. This imbalance needs to be corrected. Knowledge of uncommon diseases is important but only where the diseases illustrate important clinical or scientific principles. Knowledge of common childhood diseases and their treatment can provide an opportunity for the student to focus on health issues of local concern. It can also provide the opportunity to learn about the available sources of information on morbidity and mortality, and their limitations. This naturally leads to discussion of programmes for prevention such as immunisation and screening programmes.

Child health also provides unique opportunities for the undergraduate to learn something of the ethical and legal context of modern medical practice. Issues such as consent to treatment, intensive care and its appropriateness, and the legal protection of minors are of direct practical concern to most children's doctors.

\section{(B) CLINICAL SKILLS}

Basic clinical method

Despite technological advances, good clinical methods remains of paramount importance. The skills involved in obtaining a good history, performing a complete examination, interpreting the findings to arrive at a differential diagnosis, and formulating a plan of investigation and management are likely to remain at the heart of the diagnostic process. Paediatrics need make no apology for re-emphasising their importance to the undergraduate.

\section{Basic clinical procedures}

The range of clinical skills in child health to be expected of undergraduates is necessarily limited. However, most paediatricians would expect their students to have simple skills such as being able to dress and undress a child for examination; feed and change an infant; perform an examination of a normal neonate; make simple clinical measurements such as height, weight, and occipitofrontal circumference; and to perform a simple development assessment. Many would also expect students to be able to measure blood pressure and test urine. As childhood asthma is the commonest chronic childhood disease an ability to use the inhaled devices prescribed in childhood is not unreasonable. The GMC includes basic and advanced life support as part of their suggested core. Knowledge of life support as applied to children would therefore be appropriate.

Who should best teach these procedures? Many may be better taught by nurses or other members of the child health team, perhaps offering an opportunity to emphasise the importance of teamwork in paediatrics.

\section{(C) ATTITUDES}

'He told me I was a neurotic mother'.

'Expectations have risen and patients are concerned to understand the nature of their problems and the consequences of their treatments. The relationship between doctor and patients has changed and there is a clear duty on the doctor to be able to and willing to communicate effectively, an attribute that must be developed throughout the undergraduate course and beyond'. ${ }^{1}$

Appropriate attitudes are to be a central goal of the new curriculum. What should be the objectives in child health?

\section{Towards children and their parents}

Students should appreciate that the health care needs of children differ from those of adults and should realise the importance of minimising pain and discomfort, and the need to understand and accept uncooperative 
behaviour. Non-judgmental attitudes to parents and children should be encouraged as should the undergraduate's abilities to establish and maintain cooperative and responsible relationships with families.

\section{Towards colleagues}

In a modern child health service, effective teamwork is essential. Students should develop an appreciation of the skills and knowledge of other professional colleagues, voluntary agencies, and parent/patient groups. They should know when to seek help and be able to give and take instructions gracefully.

\section{Personal}

If education in child health is to foster continuing self education and personal development, then undergraduates must learn about sources of information about children, and have some training in critically evaluating these sources.

\section{How should these goals be taught?}

This article is not about teaching the core curriculum. However, it is difficult and artificial to think about core goals and objectives separate from the methods of teaching and examination. Clearly, a necessary shift in our educational approaches is under way: fewer didactic lectures; more small group learning; sensible use of computer assisted learning; and more learner centred and problem orientated approaches. The best approaches to teaching will necessarily depend on the subject. Clinical skills will still need clinical teaching, a form of clinical apprenticeship.

The central role of examinations should not be forgotten. Examinations will undoubtedly remain an important part of a medical student's life. Used sensibly, they can provide important opportunities to shape and direct undergraduate learning.

\section{The need for constant review and change}

The pace of change in paediatrics, as in all medicine, is frighteningly fast. Today's research finding rapidly becomes tomorrow's clinical treatment. The curriculum must be constantly reviewed if it is to remain relevant.

Paediatricians should not despair. They start with some natural advantages. Childhood medicine is rooted in change, in growth and development, and an optimistic family perspective. As knowledge of the genetic and environmental basis of disease improves, the need for early effective intervention and prevention become more obvious and the need for a good core knowledge of child health more evident.

We are grateful to those university departments who sent us copies of the aims and objectives used in their undergraduate teaching courses.

1 General Medical Council. Tomorrow's doctors. Recommendations on undergraduate medical education. London: GMC, 1993.

\section{Appendix: Checklist of possible contents} for a child health core curriculum

(A) KNOWLEDGE AND UNDERSTANDING

Growth and development

Common diseases of childhood, and their treatment

Uncommon diseases which illustrate important clinical or scientific principles

Prevention of childhood illness and maintenance of child welfare

Ethical and legal aspects of paediatrics

(B) CLINICAL SKILLS

Basic clinical methods including:

Interviewing

History taking

Physical examination

Communication including record keeping and presentation

Basic clinical procedures relevant to children:

Feeding and changing a baby

Dressing and undressing a child for examination

Measuring and plotting height, weight, and occipitofrontal circumference

Performing a simple developmental assessment

Measuring blood pressure, and routine urine testing

Use of inhaled devices commonly used in children

Basic cardiopulmonary resuscitation

\section{(C) ATTITUDES}

Development of satisfactory attitudes towards:

Children and their parents

Colleagues

Habits of self education 